\title{
Histórias da posição cientifico-acadêmica da Educação Matemática no Brasil: sistematização e perspectivas
}

\author{
Histories of the scientific and academic position of Mathematics Education in Brazil: \\ characterizations and perspectives
}

Filipe Santos Fernandes ${ }^{1}$

\begin{abstract}
Resumo
Este texto busca apresentar uma sistematização das pesquisas que centram seu interesse na produção de histórias - ou, que ocasionalmente tratam de aspectos de historicidade - da posição científico-acadêmica da Educação Matemática no Brasil. Junto a um conjunto de investigações, foi possível estabelecer cinco categorias: a) Investigações que discutem a constituição e consolidação da Educação Matemática como campo profissional e científico; b) Investigações sobre a construção de sociedades organizadas, de atuação político-institucional; c) Investigações que estudam a formação de grupos de estudo, pesquisa e trabalho em Educação Matemática; d) Investigações que analisam a inserção da Educação Matemática em programas de pós-graduação no país; e e) Investigações que, ao discutirem dimensões da pesquisa em Educação Matemática, tocam em questões da historicidade dessa área de pesquisa. Ao elaborar tal sistematização pretendemos mostrar como a Educação Matemática tem se ocupado com essa discussão, de modo a permitir que perspectivas de investigação sejam evidenciadas e outras questões de cunho historiográfico sejam colocadas. Esta sistematização decorre das ações do projeto A posição científico-acadêmica da Educação Matemática no Brasil: representações, instituições e políticas, que recebe apoio do Conselho Nacional de Desenvolvimento Científico e Tecnológico (CNPq).
\end{abstract}

Palavras-chave: Área de Pesquisa; História da Educação Matemática; História da posição científico-acadêmica da Educação Matemática; Sistematização.

\begin{abstract}
This text aims to present a characterization about researches that center their interest in the production of historical reflections - or, which occasionally deals with historicity - upon the scientific-academic position of Mathematical Education in Brazil. In addition to a set of reflections, it was possible to establish five categories: a) Studies that discuss the constitution and consolidation of Mathematical Education as a professional and scientific field; b) Reflections on the construction of organized societies, based on a political-institutional performance; c) Studies which aim to understand the formation of study and research groups, as well as the working field in Mathematical Education; d) Reflections that lead to an analysis of the Mathematical Education's insertion in Post-Graduation Programs in Brazil; And e) Reflections that, when discussing dimensions of research in Mathematics Education, touch upon questions of the historicity in this area of research. With the elaboration of this study, we intend to encourage reflection on how the Mathematical Education has been dealing with this kind of discussion, in order to allow research perspectives to be highlighted as well as other topics of historiographic nature to be placed.
\end{abstract}

Keywords: Research area; History of Mathematics Education; History of the scientific and academic position of Mathematics Education; Reviews.

\footnotetext{
${ }^{1}$ Doutor em Educação Matemática pela Universidade Estadual Paulista Júlio de Mesquita Filho (UNESP/Rio Claro). Professor da Universidade Federal de Minas Gerais (UFMG), Brasil. E-mail: fernandes.fjf@gmail.com.
} 


\section{Introdução}

As preocupações sobre a historicidade da Educação Matemática, ainda que não sejam recentes, têm se acentuado nos últimos anos. Essa inquietação historiográfica e memorialística pode ser observada, por exemplo, no crescente número de congressos, de publicações e de pessoal que assumem a História da Educação Matemática como temática, inclusive empreendendo esforços de caracterização das pesquisas que nela se inserem. No Brasil, esses esforços evidenciam-se, por exemplo, no expressivo aumento do número de trabalhos com temáticas ligadas à História da Educação Matemática em eventos nacionais; na criação de um evento especialmente relacionado com a temática, o Encontro Nacional de Pesquisa em História da Educação Matemática (ENAPHEM), que realizou em 2016 sua terceira edição; na realização no país do Congresso Ibero-americano de História da Educação Matemática (CIHEM), em 2015; ou na criação da Revista de História da Educação Matemática (HISTEMAT) e do grupo de trabalho História da Educação Matemática junto à Sociedade Brasileira de Educação Matemática (SBEM), também em 2015.

Contudo, mesmo com essa crescente preocupação e variedade, o número de trabalhos dedicados a pensar os processos históricos de constituição e de consolidação da Educação Matemática como saber no espaço científico-acadêmico é, ainda, pouco expressivo. Brito e Miorim (2016), ao mapearem a produção de teses e dissertações relacionadas à História da Educação Matemática no período entre 1984 a 2011, destacam as "histórias de grupos culturais e de comunidades de prática envolvidos com a Educação Matemática" como um dos eixos temáticos que emergem de suas análises, considerando trabalhos que investigam

[...] histórias de comunidades de professores, vinculados ou não a universidades, que se organizam em grupos de estudo e atuaram na formação de professores matemáticos; histórias de sociedades de educação matemática; histórias de comunidades étnicas que se estabeleceram no Brasil e, de algum modo, se envolveram com a educação matemática; histórias de grupos institucionais ou não que, de algum modo, se envolveram com a educação matemática. (Brito \& Miorim, 2016, p. 86)

Assim, embora existam, no cenário brasileiro, trabalhos que tratem da organização de sociedades, grupos de pesquisa e eventos científicos ou os que apresentem uma periodização para a produção científico-acadêmica brasileira em Educação Matemática, a pesquisa das autoras, em uma dimensão quantitativa, destaca que são poucas as ações que tomam a produção e a circulação desse saber como questões de pesquisa, fazendo com que a temática apareça, muitas vezes, como mera coadjuvante em investigações direcionadas a outras demandas.

Buscando contornar a pouca expressividade desses trabalhos e evidenciar o modo como as investigações em Educação Matemática têm se debruçado sobre a temática, propomos neste texto apresentar uma sistematização das pesquisas que centram seu interesse na produção de histórias - ou que ocasionalmente tratam de aspectos de historicidade - da 
DOI: http://dx.doi.org/ 10.20396/zet.v25i2.8648546

Educação Matemática como área de pesquisa no cenário científico-acadêmico brasileiro². Esta sistematização decorre das ações do projeto de pesquisa A posição científico-acadêmico da Educação Matemática no Brasil: representações, instituições e políticas, em desenvolvimento na Universidade Federal de Minas Gerais (UFMG).

Em linhas gerais, o projeto tem como objetivo elaborar compreensões de como a Educação Matemática se constitui como saber no espaço científico-acadêmico brasileiro. Assim, ao perguntar sobre como, em um dado momento histórico, um discurso legitimado pelo espaço científico-acadêmico passa a ser difundido e consolidado, estamos também perguntando sobre como a Educação Matemática determina e é determinada pelas relações de poder e pelo engendramento de saberes. É essa trama poder-saber que conferiu ao projeto uma orientação metodológica que dialoga com os trabalhos de Michel Foucault. No limite, tal projeto compõe uma agenda de investigação sobre a história da posição científico-acadêmica da Educação Matemática no Brasil (Fernandes \& Garnica, 2015).

Por isso, o conjunto de investigações, as leituras e as categorizações de nossa sistematização carregam a busca pela compreensão de como atuam os procedimentos que permitem gerar e gerir os modos de existir da Educação Matemática; procedimentos de permissão ou opressão que autorizam e legitimam alguns discursos ao mesmo tempo em que silenciam outros. Essa busca, ainda que não evidente ao longo deste texto, é o solo da sistematização apresentada e, fundamentalmente, o motivo de sua constituição.

Em um primeiro momento, faremos uma caracterização da sistematização a partir do trabalho de Garnica (2010), destacando elementos fundamentais para sua elaboração e apresentação. Depois, apresentaremos as categorizações produzidas e uma discussão sobre questões historiográficas emergentes em cada uma delas. Por fim, retomaremos as categorizações em um sentido mais amplo, tratando de suas contribuições para pensar como a pesquisa em Educação Matemática tem movimentado tais preocupações.

\section{A sistematização como exercício hermenêutico}

Uma primeira consideração, referente à própria proposta deste texto, é caracterizar a sistematização como uma direção analítica que se propõe a

[...] estudar, a partir de resíduos/manifestações/registros disponíveis [...], o modo como o campo em questão vai se delineando e, a partir desse estudo, como que numa conclusão desses esforços, explicitar ou sugerir categorias/classificações/tendências, cuja intenção precípua é apresentar, de forma às vezes sintética, às vezes descritiva, os resultados da trajetória analítica desenvolvida (Garnica, 2010, p. 261).

De tal modo, destacamos três elementos que, entendemos, devem estar presentes na elaboração de uma sistematização.

\footnotetext{
${ }^{2}$ Uma versão preliminar desta sistematização foi apresentada no Encontro Nacional de Educação Matemática, realizado São Paulo, em 2016.
} 
DOI: http://dx.doi.org/ 10.20396/zet.v25i2.8648546

O primeiro é a delimitação de um conjunto de investigações que, de algum modo, tocam em um problema comum, ainda que esse problema, o objeto da sistematização, não seja o foco principal das investigações disponíveis. Esse conjunto pode ser construído de diferentes maneiras, seguindo processos técnicos - como aqueles que buscam por palavraschave em espaços de divulgação científica; que reúnem produções de coletivos específicos, como trabalhos de um mesmo grupo de pesquisa ou programa de pós-graduação; ou que selecionam trabalhos em um recorte espaço-temporal previamente definido - ou por meio de procedimentos que envolvem a sensibilidade e a experiência do pesquisador que sugere a sistematização. Em nosso caso, seguimos pelo segundo procedimento: ao debruçarmo-nos sobre o tema em diferentes momentos, surge-nos uma coleção de investigações que julgamos pertinentes para o esboço de uma sistematização com a intenção colocada: estudar, com um olhar historiográfico, o modo como a Educação Matemática tem se ocupado com investigações que discutem a sua presença no cenário científico-acadêmico brasileiro.

Como perceberão ao longo deste texto, as investigações por nós mobilizadas são de diferentes naturezas - livros, artigos, comunicações científicas, dissertações de mestrado e teses de doutorado -, abordando temas em referenciais teórico-metodológicos muito distintos entre si. Embora nosso interesse seja estudar modos como essas investigações evidenciam aspectos de historicidade da Educação Matemática como área de pesquisa, alguns desses trabalhos não possuem uma preocupação historiográfica ${ }^{3}$, um cuidado com a produção, organização, disponibilização e análise de fontes históricas para fins de pesquisas historiográficas, bem como uma atenção aos modos de se pensar a história e sua produção (Fernandes, 2014). Apesar disso, esses trabalhos trazem importantes traços de historicidade da área de pesquisa e, por isso, atuaram na composição desta sistematização.

O segundo elemento busca levantar, em meio a esse conjunto de investigações, questões que auxiliem na elaboração de compreensões sobre o tema da sistematização. Esse levantamento é feito por meio de uma leitura atenta na qual a intenção da sistematização é sempre recolocada, como se o movimento de leitura carregasse insistentemente uma indagação que não anseia por respostas, mas por pistas. É essa insistência na pergunta e essa satisfação com o desconhecido que faz da sistematização um processo hermenêutico: ela exige um cuidado quanto aos aspectos subjacentes a qualquer leitura, posto que, no limite, a sistematização estabelece uma leitura de outras leituras.

Toda sistematização deve, como processo hermenêutico, cuidar de sua plausibilidade. Como comenta Garnica (2010, p. 266), “embora toda sistematização explicite uma compreensão, é fundamental questionarmos a plausibilidade das interpretações [...] que nos são apresentadas", e o mesmo deve acontecer, defendemos, por parte daqueles que elaboram as sistematizações. O constante questionamento da plausibilidade deve ter como norte questões como: por que este conjunto de investigações, esses registros, e não outros? Por que essas pistas, rastros, resíduos? Por que essas categorias e compreensões? Essas questões,

\footnotetext{
3 Em sua tese de doutorado, Fernandes (2014) defende a preocupação historiográfica como elemento de categorização de uma pesquisa no campo da História da Educação Matemática.
} 
DOI: http://dx.doi.org/ 10.20396/zet.v25i2.8648546

ainda que vistas por muitos como simplórias, são fundamentais para a compreensão das possibilidades de emergência de certas sistematizações e não de outras; perguntas basilares para o questionamento da plausibilidade da sistematização que se elabora.

O terceiro e último elemento é a elaboração de uma trama na qual as questões e temas vão produzindo compreensões - muitas vezes distintas daquelas de suas investigações iniciais - e possibilidades de categorização. Toda categoria, como tão amplamente discutido nas abordagens qualitativas de pesquisa, é passível de ser revisitada, já que inevitavelmente carrega as intenções daquele que categoriza: toda classificação é um exercício de poder. Não se trata, contudo, de uma tentativa de exercer poder - o que, fatalmente, pode ocorrer -, mas de um exercício cravado na própria possibilidade de construção de categorias. Quando categorizamos, selecionamos, separamos, organizamos e, na maior parte das vezes, excluímos. São essas hegemonias e exclusões que fazem da categorização um meio pelo qual o poder se exerce. Assim, destaca Garnica (2010), mais importante que a categorização produzida em uma sistematização é o exercício de elaboração dessa categorização e, indo além, a explicitação desse exercício. É nele que nós, pesquisadores, colocamos em jogo os sentidos, as alianças, os interesses e as necessidades que subjazem ao processo de sistematizar. Nesse sentido,

[...] não são necessariamente as categorias finais o que mais importa num processo de sistematização. Segundo as lições que há muito nos são dadas sobre a natureza qualitativa das pesquisas que realizamos, importa mais o processo de sistematizar (elencar materiais-base, justificar a pertinência desses materiais, elaborar uma trama analítica a partir deles e, finalmente, sistematizar todo esse percurso em categorias) que os resultados da sistematização (as categorias "em si", lidas separadamente do processo que permitiu constituí-las). [...] Se nos concentramos apenas nas fases detectadas (que são, por assim dizer, "categorias" resultantes da análise), todo o longo e cuidadoso percurso de elaborações se perde, e o trabalho torna-se uma mera periodização da produção em Educação Matemática no país (Garnica, 2010, p. 266268).

Ao analisar o modo como a pesquisa em Educação Matemática tem empreendido investigações que discutem a sua presença no cenário científico-acadêmico brasileiro, chegamos a cinco categorias, quais sejam: a) Investigações que discutem a constituição e consolidação da Educação Matemática como campo profissional e científico; b) Investigações sobre a construção de sociedades organizadas, de atuação político-institucional; c) Investigações que estudam a formação de grupos de estudo, pesquisa e trabalho em Educação Matemática; d) Investigações que analisam a inserção da Educação Matemática em programas de pós-graduação no país; e e) Investigações que, ao discutirem dimensões da pesquisa em Educação Matemática, tocam em questões da historicidade dessa área de pesquisa.

A seguir, apresentamos as principais questões e desdobramentos de cada uma delas. 
DOI: http://dx.doi.org/ 10.20396/zet.v25i2.8648546

\section{Categorias: o que nos diz e nos permite dizer o exercício de sistematizar?}

Apresentamos nesta seção as categorias anteriormente levantadas, pontuando elementos comuns e questões emergentes em cada uma delas. O leitor perceberá que, muitas vezes, haverá uma proximidade entre as questões colocadas nas distintas categorias, o que nos parece natural visto a natureza de nossa proposta: estudar pesquisas que centram seu interesse na produção de histórias - ou, que ocasionalmente tratam de aspectos de historicidade - da Educação Matemática como área de pesquisa no cenário científicoacadêmico brasileiro. Os elementos comuns e as questões emergentes serão exemplificados, por vezes, com traços de algumas das pesquisas mobilizadas.

Investigações que discutem a constituição e consolidação da Educação Matemática como campo profissional e científico

Neste grupo de investigações, encontramos uma discussão sobre os processos de constituição e de consolidação da Educação Matemática com foco na construção de um campo profissional, entendendo a emergência de uma posição subjetiva, o educador matemático, no cenário científico-acadêmico; e/ou na produção de um campo científico, levando em consideração os diferentes paradigmas de investigação, correntes de pensamento, métodos, processos, critérios de legitimação, de qualidade e de validação de resultados que compõem a pesquisa em Educação Matemática.

Nesse cenário, um trabalho de destaque é o capítulo "Breve história da Educação Matemática enquanto campo profissional e científico", de Fiorentini e Lorenzato (2007). Nele, ainda que não haja uma preocupação historiográfica, como anteriormente delineada, surgem questões que contribuem intensamente com a discussão apresentada acima:

Qual a identidade da Educação Matemática? Quais são os domínios e fronteiras da Educação Matemática? O que é ser educador matemático? Há necessidade de investigação em Educação Matemática? Quais os objetivos da pesquisa em Educação Matemática? Quais são os principais campos da Educação Matemática? Onde institucionalmente se devem desenvolver as pesquisas em Educação Matemática? Como pesquisar em Educação Matemática? (Fiorentini \& Lorenzato, 2007, p. 4-5).

Essas questões são perseguidas pelos autores ao longo do texto, de modo a apresentar uma periodização da Educação Matemática em quatro fases: 1) a gestação da EM como campo profissional (período anterior à década de 1970); 2) o nascimento da Educação Matemática (década de 1970 e início dos anos 1980); 3) a emergência de uma comunidade de educadores matemáticos (década de 1980); e 4) a emergência de uma comunidade científica em Educação Matemática (década de 1990). Como podemos notar - ainda que, aqui, apenas pelos títulos - as quatro fases elencadas pelos autores estão intrinsecamente relacionadas a aspectos profissionais e científicos da Educação Matemática. Na leitura do texto, esses aspectos tornam-se ainda mais evidentes, já que a discussão empreendida leva em consideração, no âmbito profissional, a formação de sociedades politicamente organizadas, como a Sociedade Brasileira de Educação Matemática (SBEM), e, no âmbito científico, a 
DOI: http://dx.doi.org/ 10.20396/zet.v25i2.8648546

imersão da pesquisa em Educação Matemática no cenário acadêmico, dando-se destaque à criação e à consolidação de programas de pós-graduação na área.

De profunda relação com o primeiro, o artigo "Fincando estacas: uma tentativa de demarcar a educação matemática como campo profissional e científico", de Kilpatrick (1996), busca investigar aspectos científicos e profissionais da Educação Matemática. Segundo o autor, o aspecto científico (ou acadêmico) deve levar em consideração os critérios predominantes na pesquisa atual da área, bem como definir quais desses critérios deveriam ser usados na seleção de problemas e metodologias a fim de praticar uma pesquisa de alta qualidade. $\mathrm{O}$ aspecto profissional, por sua vez, deve firmar compromissos de educadores matemáticos universitários com a formação de professores.

Neste grupo de trabalhos, exemplificado pelas descrições acima, o que está em jogo é o que se pratica na e quem pratica a pesquisa em Educação Matemática. No horizonte, essa categoria nos revela uma tentativa de valorização da pesquisa em Educação Matemática, firmando sua presença e reconhecendo sua importância no cenário científico-acadêmico. Nesse processo, surgem temáticas que buscam entender como a área de pesquisa se constitui nas inter-relações com campos já consolidados, compartilhando problemas, métodos e examinando as aproximações e os distanciamentos a critérios de cientificidade postos. Ainda que não haja, em geral, uma preocupação historiográfica nas investigações deste conjunto, é possível perceber traços de historicidade no relevo dado a episódios político-institucionais, como a criação de programas de pós-graduação ou de linhas de pesquisa em programas já existentes, de sociedades organizadas e de grupos que - talvez apenas aos olhares do presente - atuavam em uma área emergente denominada Educação Matemática.

Investigações sobre a construção de sociedades organizadas, de atuação políticoinstitucional

Neste conjunto, surgem investigações sobre os processos históricos de construção de sociedades profissionais organizadas que, em geral, têm atuação político-institucional. No Brasil, há uma predominância de olhares para a década de 1980 e períodos posteriores, já que os anos de 1980 marcam os movimentos de organização da Sociedade Brasileira de Educação Matemática (SBEM), fundada em 1988.

Uma pesquisa que evidencia as preocupações dessa categoria de trabalhos é a tese de doutorado "História do movimento democrático que criou a Sociedade Brasileira de Educação Matemática" (Pereira, 2005). O trabalho, de natureza historiográfica, destaca os esforços e articulações do período que vai de 1985, ano de realização da VI Conferência Interamericana de Educação Matemática (Guadalajara/México) e que marca o início das articulações para a construção da sociedade, a 1988, ano de fundação da SBEM. Evidenciamse no texto o jogo de posições, as concordâncias e os conflitos do processo de construção da Sociedade. Nessa perspectiva e tomando as palavras do autor, "a SBEM é o nome dessa [...] resultante de um processo de posições distintas, não necessariamente de grupos distintos. Como poderiam os grupos existir antes de defender posições? Pois é o trabalho efetivo de defesa de posições que constitui os grupos, e não o contrário" (Pereira, 2005, p. 252). 
DOI: http://dx.doi.org/ 10.20396/zet.v25i2.8648546

Outros dois trabalhos que destacaremos tratam de movimentos de criação de regionais da SBEM. O primeiro é a pesquisa de iniciação científica intitulada "A história da Sociedade Brasileira de Educação Matemática no Rio Grande do Norte", desenvolvida por Souza e Gutierre (2014). O trabalho revelou que a proposta de criação da regional da SBEM no Rio Grande do Norte esteve diretamente ligada aos interesses do professor Antônio Pinheiro de Araújo que, em 1990, após a realização, em Natal, do III Encontro Nacional de Educação Matemática, movimentou-se na direção dessa criação, ainda que não bem sucedida. A regional foi fundada apenas em 2004, com o apoio da professora Arlete de Jesus Brito e de professores da região. O segundo, a pesquisa de mestrado "Sociedade Brasileira de Educação Matemática do estado de Mato Grosso do Sul: três caricaturas e muitas histórias" (Larrea, 2015), busca compreender o processo de criação e atuação da regional da SBEM no Mato Grosso do Sul mobilizando depoimentos e fontes escritas disponibilizadas em acervos. A autora aponta modos distintos e complementares pelos quais os processos históricos da criação da SBEM/MS podem ser compreendidos. Esses modos levam em conta, fundamentalmente, questões como as ações efetivas e simbólicas da regional e as possibilidades e entraves dessas ações.

Nesta categoria, destacamos trabalhos que se associam fortemente à criação e à atuação da SBEM, seja no âmbito nacional ou regional. Diferentemente da categoria anterior, há neste grupo uma preocupação historiográfica, sendo seu revelo dado por personagens e acontecimentos que permitem identificar as preocupações político-institucionais dessas sociedades. Apesar de já existir uma riqueza de dados nesta categoria, acreditamos que ela ainda careça de olhares em outras direções e perspectivas. Uma possível direção, mais evidente, seria a construção de histórias das mais diferentes regionais da SBEM, inclusive revisitando histórias já contadas; outra, correlata à primeira, levaria em consideração o insucesso ou silenciamento em movimentos de constituição destes grupos, como ocorrido na história produzida sobre a regional da SBEM do Rio Grande do Norte. Há, ainda, uma possibilidade de mudança de perspectiva, mais ousada e delicada, que poderia abordar grupos institucionais não ligados à SBEM, como comissões vinculadas a órgãos governamentais que tratem de aspectos político-institucionais da Educação Matemática, como os de ordem pública, curricular, formativa e outras.

Investigações que estudam a formação de grupos de estudo, pesquisa e trabalho em Educação Matemática

Nesta categoria, encontramos trabalhos que discutem a criação, a atuação e, por vezes, a extinção de grupos de estudo, pesquisa e trabalho em Educação Matemática em associações e instituições educacionais ou de pesquisa no Brasil.

Para tratar das dimensões desta categoria, citamos dois trabalhos. O primeiro, a tese de doutorado desenvolvida por Silva (2006), explora a identidade do "Centro de Educação Matemática" (CEM), grupo que atuou na cidade de São Paulo entre os anos de 1984 e 1997 e que prestou serviços de assessoramento e consultoria especializada em Educação Matemática para instituições escolares e governamentais. A tese, que mobiliza a História Oral como metodologia, é composta de quinze narrativas de participantes do grupo. O modo de explorar 
DOI: http://dx.doi.org/ 10.20396/zet.v25i2.8648546

a identidade do CEM, contudo, não se dá de maneira unidirecional: com mobilizações de diferentes teóricos, posições e abordagens, a autora tece diferentes identidades ao grupo, partindo de quatro marcos teóricos distintos. Essas identidades, como comenta a autora, não se legitimam e tampouco se negam, sendo a área de pesquisa em Educação Matemática, pensada no âmbito das práticas e dos praticantes que compõem o CEM, discutida através de distintos olhares.

O segundo compõe parte do artigo "A educação matemática: breve histórico, ações implementadas e questões sobre a sua disciplinarização" (Miguel, Garnica, Igliori \& D’Ambrosio, 2004). No texto, há uma discussão sobre a criação do grupo de trabalho em Educação Matemática na Associação Nacional de Pós-graduação e Pesquisa em Educação (ANPEd). Essa discussão traz posicionamentos em duas direções: a que entende a criação do grupo como possibilidade de produção de um espaço de considerável divulgação da pesquisa em Educação Matemática e a que defende a inserção dos trabalhos em Educação Matemática nos grupos já existentes, sendo indesejável o isolamento ocasionado pela criação de um grupo específico.

Ao abordarem processos de criação e atuação de grupos - reuniões de pessoas com interesses comuns -, as pesquisas desta categoria, em geral, evidenciam diferentes posições sobre questões ligadas à especificidade Educação Matemática, como sua vinculação ou subordinação a outras áreas do conhecimento que revelam, no limite, uma profunda discussão epistemológica. Além da declarada intenção de narrar uma história, essas investigações destacam a atuação desses grupos na constituição e consolidação da área de pesquisa, mostrando articulações e resistências de sua atuação em diferentes contextos institucionais. Frequentemente, o relevo historiográfico, sustentado por alianças e rupturas, privilegia histórias de grupos vinculados a associações e instituições de amplo reconhecimento. Nesse ponto, em especial, destacamos que seria interessante considerar o desenvolvimento de trabalhos que abordem a movimentação histórica de grupos em que as vinculações institucionais são menos visíveis ou reconhecíveis, tratando de uma Educação Matemática exercida em espaços de menor visibilidade.

Investigações que analisam a inserção da Educação Matemática em programas de pósgraduação no país

Como pontuamos anteriormente, os programas de pós-graduação são importantes elementos para a compreensão da Educação Matemática como campo científico, sendo tratados como marcos que situam a área em um cenário científico-acadêmico geral. Nesta categoria, a inserção e a consolidação da Educação Matemática junto aos programas de pósgraduação não são tratadas apenas como marcos, mas constituem a centralidade das investigações desenvolvidas. Trata-se, portanto, de pesquisas que formulam problemas em torno das relações estabelecidas no movimento de criação e atuação de programas de pósgraduação específicos ou de linhas de pesquisa em programas já existentes.

Um trabalho que toca nessa problemática foi desenvolvido por Miranda (2015) e estuda o primeiro mestrado em Ensino de Ciências e Matemática da UNICAMP, no período 
DOI: http://dx.doi.org/ 10.20396/zet.v25i2.8648546

de 1975 a 1984. O autor explora o tema em duas direções: em uma delas, discute como as investigações em Educação Matemática desenvolvidas nesse programa dizem da Educação Matemática do período, especialmente seus personagens, temas e problemas; em outra, trata de como esse programa de pós-graduação marcou a presença da Educação Matemática no espaço científico-acadêmico brasileiro, delineando seus caminhos futuros.

Outro trabalho, a pesquisa de mestrado desenvolvida por Britto (2010), aborda as perspectivas de consolidação da Educação Matemática como campo de pesquisa no programa de pós-graduação em Educação da Universidade Federal de Minas Gerais. Produzida junto a uma série de documentos - atas, depoimentos, questionários e outros -, a investigação, além de discutir questões das pesquisas desenvolvidas no âmbito desse programa, evidencia uma sintonia entre essas questões e um movimento mais amplo que se verifica nacionalmente, o que sustenta e fortalece as questões ligadas à consolidação da Educação Matemática como uma das linhas de pesquisa do programa de pós-graduação em Educação da UFMG.

No tocante às investigações que se inserem neste grupo, entendemos que a análise cuidadosa das questões e discussões que envolvem a produção de pesquisas no âmbito de programas de pós-graduação no país permite estabelecer compreensões sobre a posição da Educação Matemática em instituições de ensino superior. Ainda que haja uma preocupação sobre a criação/ampliação dos espaços da Educação Matemática, como nos trabalhos de Miranda (2015) e Britto (2010), há ainda uma carência de discussões que toquem em outras questões: Como se dá o movimento de criação/ampliação de espaços para a Educação Matemática no Brasil? Como diferentes instituições brasileiras, antigas e atuais, instauram esses espaços (físicos e subjetivos) no qual os educadores matemáticos circulam? Pensar essas questões permitiria tecer considerações mais expressivas sobre as demandas que tocam a circulação e afirmação da pesquisa em Educação Matemática na pós-graduação brasileira.

Investigações que, ao discutirem dimensões da pesquisa em Educação Matemática, tocam em questões da historicidade dessa área de pesquisa

Nesta última categoria, situamos os trabalhos que, ao discutirem dimensões da pesquisa em Educação Matemática - como aquelas de ordem filosófica, epistemológica, científica, entre outras -, tocam em aspectos de historicidade da área de pesquisa. Neste grupo, ainda que não exista, muitas vezes, uma preocupação historiográfica, podemos separar diversos elementos que dizem da Educação Matemática como agente e efeito de processos históricos.

Um dos trabalhos que consideramos como mais relevantes nesse cenário é a pesquisa de doutorado de Venturin (2015), intitulada "A Educação Matemática no Brasil da perspectiva do discurso de seus pesquisadores". Nela, o autor trata de diversas dimensões especialmente aos de ordem filosófica - da área de pesquisa e, ao abordá-las, contribui com perspectivas da historicidade da Educação Matemática. Essas perspectivas são abertas, principalmente, nos diversos significados evidenciados nos discursos dos pesquisadores, nas relações e estilos que vão se compondo para a elaboração de uma área de pesquisa. A 
DOI: http://dx.doi.org/ 10.20396/zet.v25i2.8648546

Educação Matemática não é, então, tratada de modo isolado, mas produzida junto às relações dos sujeitos que a vivenciam.

É importante destacar, ainda, que o trabalho de Venturin (2015) insere-se em um projeto maior desenvolvido pelo Grupo de Pesquisa Fenomenologia e Educação Matemática (FEM). Ao propor a interrogação "O que é a pesquisa em Educação Matemática no Brasil?" (Bicudo \& Paulo, 2011), o grupo tem instaurado um exercício filosófico que busca "fornecer subsídios para se pensar a pesquisa em Educação Matemática no Brasil, principalmente em nível institucional, entendido como sendo aquele de instância nacional que reúne os pesquisadores do país" (Bicudo \& Paulo, 2011, p. 255). Note-se que tal proposta não desvincula os aspectos filosóficos que circunstanciam a pesquisa em Educação Matemática, especialmente os que tangem sua cientificidade, dos aspectos históricos de sua constituição.

Em certo sentido, podemos observar um tratamento semelhante ao de Venturin (2015) nas teses de Vianna (2000) e Fernandes (2014). O trabalho de Vianna (2000) reúne narrativas de vida de quinze educadores matemáticos que atuam em departamentos/institutos de Matemática de universidades brasileiras. $\mathrm{O}$ autor suspeita que os professores, atuando dentro desses espaços e optando por exercer atividades no campo da Educação Matemática, sofrem resistências institucionais, pessoais e profissionais, produzindo dificuldades variadas no desenvolvimento de suas atividades. Contudo, para além da questão colocada, há uma evidente problematização na tese da relação sobre aspectos de cientificidade: a Educação Matemática parece não assumir uma forma definida, mas uma forma múltipla que se prolifera em diversificados pontos de vista, personagens, abordagens e compreensões. No princípio da tese, o autor propõe um jogo no qual nós, leitores, temos que associar trechos que dizem das concepções de Educação Matemática - trechos que foram cortados das textualizações das entrevistas e apresentados em outro momento da tese - a seus respectivos colaboradores. Seríamos nós, leitores, capazes de associar as concepções de Educação Matemática à vida de cada pesquisador? A vida, em suas circunstâncias, promove formas singulares de existência da Educação Matemática?

O trabalho de Fernandes (2014), por sua vez, buscou elaborar compreensões de como a Educação Matemática se constitui no espaço científico-acadêmico brasileiro. Metodologicamente, foram mobilizados memoriais de Livre-docência de pesquisadores em Educação Matemática; memoriais que foram analisados e reescritos para fornecerem a base de uma entrevista com esses pesquisadores. As textualizações apresentadas na tese, entremeadas de excertos do memorial, constituíram-se como solo para a pesquisa e como pano de fundo para a elaboração de compreensões. Essas compreensões seguiram um movimento que coloca como centro a experiência da narrativa, isto é, o modo como essas textualizações disparavam questões e compreensões sobre a Educação Matemática como área de pesquisa. Esses modos são expressos em cinco histórias da Educação Matemática, narradas na perspectiva de uma estética ficcional.

Nesses trabalhos, destaca-se a atenção aos modos como múltiplas formas de subjetivação são talhadas no tempo, delineando formas de existir não só para a Educação Matemática, mas para os sujeitos que dela participam. Aqui, as questões de ordem Zetetiké, Campinas, SP, v.25, n.2, mai./ago.2017, p.222-239

ISSN 2176-1744 
DOI: http://dx.doi.org/ 10.20396/zet.v25i2.8648546

epistemológica encontram-se com as subjetivas e permitem produzir cenários diversos para a Educação Matemática, pensando a constituição e consolidação da área ao mesmo tempo em a vida dos sujeitos que dela participam é produzida. No limite, trata-se de uma ruptura com epistemologias que postulam o conhecer antes do ser, permitindo histórias que colocam em cena a descontinuidade e a contingência no lugar da continuidade e da fatalidade.

\section{Histórias da posição científico-acadêmica da Educação Matemática no Brasil: pontuando perspectivas}

Ao longo deste texto, buscamos levar em consideração os desdobramentos de diversas pesquisas para pensar uma temática emergente no campo da História da Educação Matemática: a produção de histórias sobre a posição científico-acadêmica da Educação Matemática no Brasil. Como destacamos, as pesquisas apresentadas não representam a totalidade das investigações mobilizadas, e tampouco configuram categorias fixas e bem definidas: muitos trabalhos poderiam não se enquadrar nessas categorias, mesmo compartilhando de muitas das questões aqui destacadas. A proposta da categorização, decorrente desta sistematização, tem a simples pretensão de evidenciar como alguns trabalhos têm se ocupado com a problemática, permitindo que algumas perspectivas sejam colocadas com maior evidência.

Uma dessas perspectivas está relacionada à preeminência de elementos de ordem sociológica, que ganham especial destaque quando comparados aos ordem epistemológica. Assim, em geral, investigar a história da Educação Matemática no cenário científicoacadêmico passa pela compreensão dos processos de construção de uma comunidade, a dos pesquisadores em Educação Matemática. Ainda que não apresente uma matriz epistemológica bem definida, linguagem própria e métodos singulares de pesquisa, a Educação Matemática é uma prática de pesquisa com nítidas configurações, em nível nacional e internacional: há pesquisadores, grupos de pesquisa, programas de pós-graduação, sociedades organizadas e reconhecimento por agências de fomento à pesquisa e órgãos governamentais voltados a esse fim. Essa configuração permite, então, que elementos sociológicos permeiem as histórias produzidas, buscando reconhecer as "principais características que definem a identidade social de uma comunidade de prática científicoacadêmica, bem como as características do processo de institucionalização da pesquisa acadêmica em nosso país e no mundo contemporâneo" (Miguel, 2008, p. 391).

Essa preeminência dos elementos sociológicos é percebida em diferentes categorias de investigações aqui construídas: nos que discutem a constituição e consolidação da Educação Matemática como campo profissional e científico, os processos de periodização propostos para a área de pesquisa levam em consideração marcos de modificação na qualificação dos profissionais da área, em geral ligados à formação e circulação de mestres e doutores; naqueles que discutem a construção de sociedades organizadas, destaca-se a formação da SBEM e sua importância na produção de uma identidade profissional; nos que estudam a formação de grupos de estudo, pesquisa e trabalho em Educação Matemática ou nos que analisam a inserção da Educação Matemática em programas de pós-graduação no país, o 
DOI: http://dx.doi.org/ 10.20396/zet.v25i2.8648546

argumento sociológico firma-se nos diferentes processos de formação de grupos que buscam, no limite, firmar uma posição identitária. Segundo a análise que empreendemos, os trabalhos que discutem certas dimensões da pesquisa em Educação Matemática parecem ser os únicos nos quais os elementos epistemológicos aparecem com maior ênfase.

Outra perspectiva está vinculada ao olhar cuidadoso traçado para as décadas de 1980 e 1990, período marcado por um nó que articula diversos acontecimentos e que parece instaurar um solo que permitiu a emergência da Educação Matemática no espaço científico-acadêmico brasileiro. Possivelmente, esse recorte temporal aproxima essas pesquisas de uma dimensão metodológica que foca, prioritariamente, acontecimentos e grupos locais.

Mesmo sendo evidente a crescente organização de núcleos de pesquisa em Educação Matemática em programas de pós-graduação em Educação ou Matemática em períodos anteriores à década de 1980, a criação de programas de pós-graduação específicos em Educação Matemática promove a formação e circulação de mestres e doutores em Educação Matemática, contribuindo, assim, com a composição da posição subjetiva do educador matemático. Essa posição vem associada à criação da SBEM, resultado de esforços de pesquisadores do período para a construção da Educação Matemática por meio da organização profissional vinculada a uma sociedade. Ainda que não se configure como campo profissional autônomo, a fundação de uma sociedade organizada e politicamente ativa parece atuar como um importante agente no reconhecimento da Educação Matemática como saber institucionalizado.

Evidentemente, poderíamos destacar nas cercanias do período citado - décadas de 1980 e 1990 - outros acontecimentos, como os movimentos na área de Ensino de Ciências e Matemática ocorridos nas décadas de 1970 e 1980; a criação dos Centros de Ensino de Ciências, ainda na década de 1960, que apresentavam uma emergente discussão sobre a formação de professores nessas áreas; ou as próprias discussões educacionais que surgiam em meio ao Movimento da Matemática Moderna. Esses, não menos importantes, são indícios que contribuem para pensar como uma série de acontecimentos históricos - difusos, caóticos, momentâneos, concomitantes ou não - possibilitaram a constituição da Educação Matemática.

De tal modo, o processo de construção dessas histórias parece estar profundamente ligado à delimitação de posições subjetivas e de espaços nos quais esses sujeitos podem circular. $\mathrm{O}$ interesse pelas perspectivas acima mencionadas - o destaque aos aspectos sociológicos e o período que compreende as décadas de 1980/1990 - mostra a relação estabelecida entre a produção de saberes, marcada pelas discussões que envolvem a constituição e consolidação da Educação Matemática como campo profisssional e científico; as relações poder, que permeiam a construção de sociedades organizadas, a inserção da área em programas de pós-graduação no país e a formação de grupos de estudo, pesquisa e 
DOI: http://dx.doi.org/ 10.20396/zet.v25i2.8648546

trabalho; e as vias de institucionalização ${ }^{4}$ da Educação Matemática nas diferentes instâncias nacionais que reúnem pesquisadores. Ainda que seja insuficiente propor uma leitura mais profunda desse interesse a partir de tais categorias, elas nos direcionam a uma preocupação com os processos históricos de constituição da Educação Matemática como saber.

Fundamentado no exposto no parágrafo anterior, o projeto de pesquisa $A$ posição científico-acadêmico da Educação Matemática no Brasil: representações, instituições e políticas, em desenvolvimento na Universidade Federal de Minas Gerais (UFMG), propõe elaborar compreensões de como se dá a emergência do educador matemático - a posição subjetiva institucionalizada e autorizada a produzir, a divulgar e a legitimar esse saber - no espaço científico-acadêmico brasileiro. Essa elaboração passa pelo estabelecimento dos nós que articulam acontecimentos e instauram um solo no qual as edificações de poderes e saberes se sustentam e transitam. Tendo em vista esse aspecto tão considerável - a relação poder-saber - propomos um possível caminho que encontra nos princípios de regulação do discurso descritos por Michel Foucault seu principal embasamento. Trata-se, portanto, de uma indagação sobre como, em um dado momento histórico, um discurso legitimado pelo espaço científico-acadêmico passa a ser difundido por meio de sutis mecanismos que constituem, articulam, organizam e fazem circular poderes e saberes.

Assim como o conjunto de pinturas de Cézanne que apresentaremos a seguir, esperamos que esta sistematização seja apenas um anúncio de possibilidades de investigação, permitindo-nos territórios provisórios pelos quais podemos transitar e pensar a pesquisa sobre a posição científico-acadêmica da Educação Matemática no Brasil. O relevo dado pelos aspectos sociológicos e pelo período compreendido entre as décadas de 1980 e 1990 são apenas paisagens provisórias que podem, ao mesmo tempo, afirmar ou subverter certas geografias do passado. Afinal, como destaca Albuquerque Jr. (2007, p. 87):

Devemos aprender com outro poeta, como tu, chamado Michel Foucault, que a História deve tratar das descontinuidades que nos constituíram, da multiplicidade de experiências disparatadas e sem roteiro próprio que tornou possível ser como somos; que a História deve descrever os desenhos, o relevo formado pelo depósito constante de camadas de discursos, pela sedimentação das memórias em textos e em todas as formas de linguagem, que, ao se acumularem, como cisco se acumula em pés de parede formando monturos, produzem uma geografia do passado, dão a ele consistência de pedra, de bronze ou de granito, dificultando a percepção de pequenos grãos, dos pequenos sedimentos, dos pequenos gestos, de múltiplas ações, reações, conflitos, pelejas, sonhos, vidas que o constituíram como unidade de fato e de sentido.

\footnotetext{
${ }^{4}$ Como em Bicudo \& Paulo (2011, p. 225), a ideia de institucionalização está ligada às instâncias nacionais que reúnem pesquisadores do país. No Brasil, usualmente, essa reunião ocorre em universidades e centros de pesquisa independentes.
} 


\section{Encerrando: Paul Cézanne}

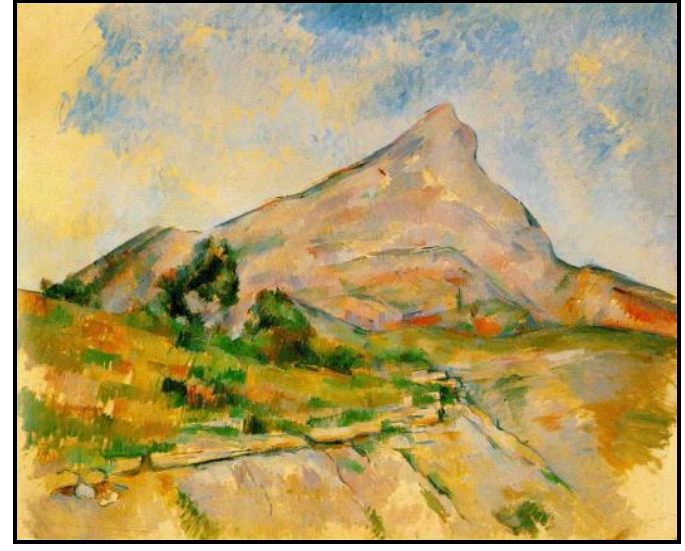

Le Mont Sainte-Victoire, 1897-98.

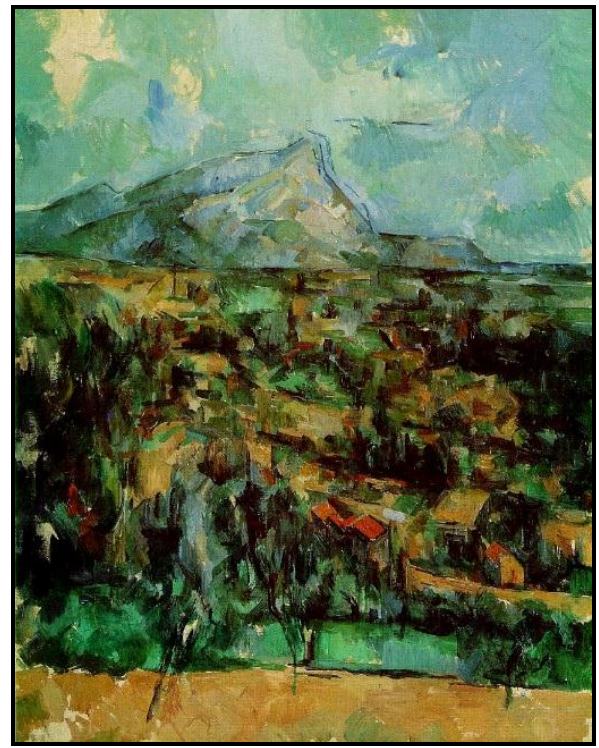

Mont Sainte-Victoire, 1902.

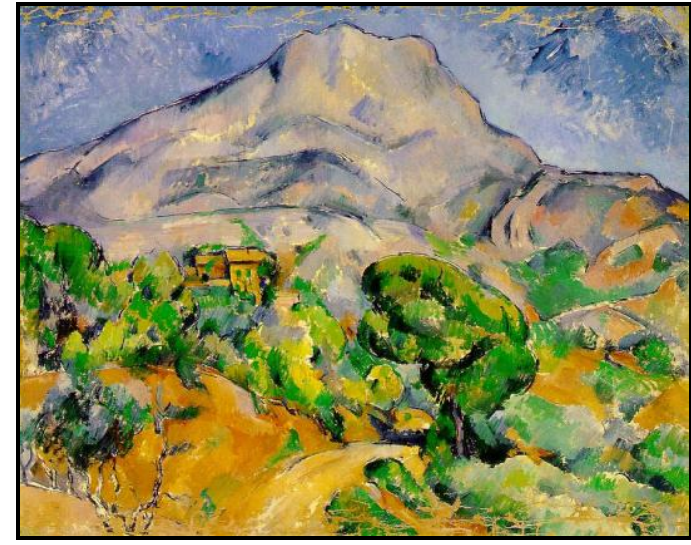

Mont Sainte-Victoire, 1900.

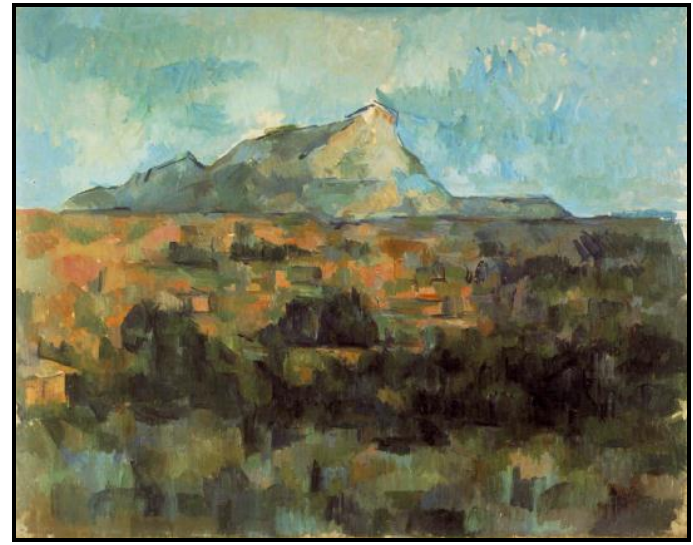

Mont Sainte-Victoire, 1904-06.

O pintor Paul Cézanne (1839-1906) dedicou uma série de pinturas ao Monte SainteVictoire, uma montanha ao sul da França de grande importância na vida do artista. Representado em várias perspectivas e formas, o que mais chama a atenção nessa coleção de pinturas é o comprometimento do pintor com o inacabamento do traço que a região assume.

Entre as pinturas e em cada uma delas, linhas e formas que podem ou poderiam compor as figuras representadas sempre nos escapam ao olhar. Assim, em várias, os contornos da montanha e do céu parecem confundir-se, permitindo-nos apenas uma dissociabilidade momentânea, mas nunca precisa, dos limites de Sainte-Victoire. Em tantas outras, no entanto, insinua-se mais destacadamente a organização das casas, das vielas e até mesmo do tipo de vegetação que compõe a paisagem do vilarejo na base da montanha. Daqui, 
DOI: http://dx.doi.org/ 10.20396/zet.v25i2.8648546

talvez, decorre o impressionismo do pintor: apreender um momento e não uma forma; fazer duração um curto espaço de tempo.

Ao esboçar esta sistematização não buscamos por uma forma definida ou definitiva, mas pela apreensão de um momento que tinha na direção do olhar uma questão e nas mãos algumas possibilidades de escrita. Assim como o Monte Sainte-Victoire de Cézanne nos convida ao inacabamento, buscamos evidenciar como nossas experiências e sentidos permitiram a elaboração de compressões de um cenário de pesquisa que podem ser insistentemente revistado. Sistematizar é lançar-se na direção de uma questão e reunir diferentes materialidades para produzir cenários transitórios, inacabados e imprevisíveis: geografias do passado que se confundem com o presente...

Esperamos, por fim, que essa sistematização forneça elementos e questões para os interessados pelas histórias da posição científico-acadêmica em Educação Matemática no Brasil, contribuindo com a pesquisa em História da Educação Matemática e abrindo possibilidades de investigação que tenham como compromisso o cuidado ético, estético e político de uma comunidade com seus modos de constituição e consolidação.

\section{Referências}

Albuquerque Jr., D. M. (2007). História: a arte de inventar o passado. Bauru: Edusc.

Brito, A. J. \& Miorim, M. A. (2016). A institucionalização da Educação Matemática. In: A. V. M. Garnica (Org.), Pesquisa em História da Educação Matemática: sob o signo da pluralidade, pp. 67-92. São Paulo: Editora Livraria da Física.

Fernandes, F. S. (2014). A quinta história: composições da Educação Matemática como área de pesquisa. Tese de Doutorado em Educação Matemática. Rio Claro: Universidade Estadual Paulista "Júlio de Mesquita Filho". Retirado em 11 de março, 2017, de: http://repositorio.unesp.br/handle/11449/123819.

Fernandes, F. S. \& Garnica, A. V. M. (2015). History of Scientific and Academic Production in Mathematics Education: pointing out elements for a research agenda. International Journal for Research in Mathematics Education, 5(1), 2-11.

Garnica, A. V. M. (2010). Outras inquisições: apontamentos sobre História Oral e História da Educação Matemática. Zetetiké, 18(34), 259-304.

Miguel, A. (2008). Áreas e subáreas do conhecimento, vínculos epistemológicos: o GT de Educação Matemática da ANPEd. Revista Brasileira de Educação, 13(38), 387-414.

\section{Referências mobilizadas nesta sistematização}

Bicudo, M. A. V. \& Paulo, R. M. (2011). Um exercício filosófico sobre a pesquisa em Educação Matemática no Brasil. Bolema: Boletim de Educação Matemática, 25(41), 251-298.

Britto, F. A. (2010). Perspectivas de consolidação da Educação Matemática como campo de pesquisa no programa de pós-graduação em Educação da UFMG. Dissertação de Mestrado em Educação. Belo Horizonte: Universidade Federal de Minas Gerais. 
DOI: http://dx.doi.org/ 10.20396/zet.v25i2.8648546

Retirado em 11 de março, 2017, de: http://www.bibliotecadigital.ufmg.br/dspace/handle/1843/BUDB-8CBRTS.

Fernandes, F. S. (2014). A quinta história: composições da Educação Matemática como área de pesquisa. Tese de Doutorado em Educação Matemática. Rio Claro: Universidade Estadual Paulista "Júlio de Mesquita Filho". Retirado em 11 de março, 2017, de: http://repositorio.unesp.br/handle/11449/123819.

Fiorentini, D. \& Lorenzato, S. (2007). Breve história da Educação Matemática enquanto campo profissional e científico. In D. Fiorentini \& S. Lorenzato (Orgs.), Investigação em Educação Matemática: percursos teóricos e metodológicos, pp. 15-40. Campinas: Autores Associados.

Kilpatrick, J. (1996). Fincando estacas: uma tentativa de demarcar a educação matemática como campo profissional e científico. Zetetiké, 4(5), 99-120.

Larrea, N. T. (2015). Sociedade Brasileira de Educação Matemática do estado de Mato Grosso do Sul: três caricaturas e muitas histórias. Dissertação de Mestrado em Educação Matemática. Campo Grande: Universidade Federal de Mato Grosso do Sul. Retirada em 11 de março, 2017, de: http://bdtd.ibict.br/vufind/Record/UFMS_ab64654291c1f7e875813a9882aa1858.

Miguel, A.; Garnica, A. V. M.; Igliori, S. B. C. \& D’Ambrosio, U. (2004). A educação matemática: breve histórico, ações implementadas e questões sobre a sua disciplinarização. Revista Brasileira de Educação, 27, 70-93.

Miranda, G. A. (2015). Passos embrionários da pesquisa em Educação Matemática no Brasil: personagens e produções do primeiro mestrado em Ensino de Ciências e Matemática da Unicamp. Anais do $6^{\circ}$ Seminário Internacional de Pesquisa em Educação Matemática (pp. 1-12). Pirenópolis: Sociedade Brasileira de Educação Matemática. Retirado em 11 de março, 2017, de: http://www.sbembrasil.org.br/visipem/anais/story_html5.html.

Pereira, D. J. R. (2005). História do movimento democrático que criou a Sociedade Brasileira de Educação Matemática (SBEM). Tese de Doutorado em Educação. Campinas: Universidade Estadual de Campinas. Retirado em 11 de março, 2017, de: http://www.bibliotecadigital.unicamp.br/document/?code=vtls000392535.

Silva, H. (2006). Centro de Educação Matemática (CEM): fragmentos de identidade. Tese de Doutorado em Educação Matemática. Rio Claro: Universidade Estadual Paulista "Júlio de Mesquita Filho". Retirado em 11 de março, 2017, de: http://repositorio.unesp.br/handle/11449/102135.

Souza, J. C. R. \& Gutierre, L. S. A. (2014). História da Sociedade Brasileira de Educação Matemática do Rio Grande do Norte. Anais do $2^{\circ}$ Encontro Nacional de Pesquisa em História da Educação Matemática (pp. 868-874). Bauru: Universidade Estadual Paulista "Júlio de Mesquita Filho". Retirado em 11 de março, 2017, de: http://www2.fc.unesp.br/enaphem/anais/.

Venturin, J. A. (2015). A Educação Matemática no Brasil na perspectiva de seus pesquisadores. Tese de Doutorado em Educação Matemática. Rio Claro: Universidade Estadual Paulista "Júlio de Mesquita Filho". Retirado em 11 de março, 2017, de: http://repositorio.unesp.br/handle/11449/134027. 
DOI: http://dx.doi.org/ 10.20396/zet.v25i2.8648546

Vianna, C. R. (2000). Vidas e circunstâncias na Educação Matemática. Tese de Doutorado em Educação. São Paulo: Universidade de São Paulo. Retirado em 11 de março, 2017, de: http://bdpi.usp.br/single.php?_id=001098364. 